\title{
Two-port network model of wind turbine generator for three- phase unbalanced distribution system load flow analysis
}

\author{
Rudy Gianto, Purwoharjono \\ Department of Electrical Engineering, Tanjungpura University, Pontianak, Indonesia
}

\begin{abstract}
Article Info
Article history:

Received May 19, 2021

Revised Oct 12, 2021

Accepted Jan 6, 2022

Keywords:

Induction generator

Load flow

Three-phase distribution system

Two-port network

Wind turbine generator

ABSTRACT

An unbalanced electric power system can occur due to unequal lines and/or loads in each phase of the system. For a system with a high level of unbalance, the assumption that the system is balanced becomes incorrect. For a case like this, the system must be analyzed using three-phase approaches because single-phase analysis techniques can no longer be used to obtain accurate results. Therefore, the development of three-phase models of all components of the electric power system, including the wind turbine generating system (WTGS), is very important so that the system can properly be analyzed and its performance can correctly be evaluated. This paper proposes a method to incorporate WTGS in a three-phase load flow analysis of an unbalanced distribution system. The proposed method is based on the previously published single-phase two-port network model. In this paper, the single-phase two-port network model is modified and extended so that it can be applied to unbalanced systems. The model is then included in the three-phase distribution system load flow (DSLF) analysis. The proposed method is validated using 12-node and 19-node distribution systems.
\end{abstract}

This is an open access article under the CC BY-SA license.

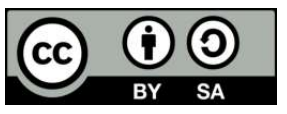

\section{Corresponding Author:}

Rudy Gianto

Department of Electrical Engineering, Tanjungpura University

Jalan Prof. Dr. H. Hadari Nawawi, Pontianak 78124, Kalimantan Barat, Indonesia

Email: rudy.gianto@ee.untan.ac.id

\section{INTRODUCTION}

It has been well acknowledged that penetration of wind turbine generating system (WTGS) in the electric power system will complicate the assessment and evaluation of the power system steady state and dynamic performances. This complication can be more profound in unbalanced electric power distribution systems since three-phase techniques have to be used in the analyses. An unbalanced electric power system generally occurs due to unequal lines and/or loads in each phase of the power system. For a system with a high level of unbalance, the assumption that the system is balanced becomes incorrect. For a case like this, the electric power system must be analyzed using three-phase approaches because single-phase analysis techniques can no longer be used to obtain accurate results [1].

To assess and evaluate the system steady state and dynamic performances of a power system embedded with WTGS, all of the system components (including the WTGS) need to properly be modeled [2]. In recent years, many investigations have been conducted in the context of modeling and integrating WTGS into steady state load flow analysis of an electric power system. For example, references [3]-[21] propose interesting methods to incorporate WTGS into load flow analysis. In [3]-[5], the induction generator equivalent circuit of the WTGS is converted to a three-node model. The three-node model application will modify the load flow analysis due to the addition of two branches and two PQ nodes to the original power 
system where the WTGS is connected. With this method, a traditional load flow program can be used to solve the load flow problem, and modifications to the program source code are therefore not required.

In [6]-[16], several steady-state mathematical models of fixed speed WTGS for load flow analyses have been developed. In the analyses, the equations of the WTGS models, combined with the existing power system equations (i.e., power system equations without the WTGS), are solved using some non-direct or iterative techniques. References [6]-[13] propose models which are formed based on the D or $\Pi$ equivalent circuit of the WTGS induction generator. Reference [14] also proposes a steady-state model of fixed speed WTGS for load flow analysis. The model in [14] is derived based on the theory of a two-terminal network (or two-port network). In [15], [16] propose WTGS load flow models, which are obtained based on the Y or T equivalent circuit of the WTGS induction generator. The model in [15], [16] is derived using Kirchhoff and Ohm laws. In [17]-[21], DFIG-based variable speed WTGS models for steady state load flow analysis have been proposed. Equivalent circuits of the doubly fed induction generator (DFIG) have also been used in developing the models in [17]-[21].

All of the WTGS models proposed in [3]-[21] assume that the system was balanced so that singlephase load flow techniques can be used to analyze it. However, as mentioned earlier, the electric power distribution system is generally unbalanced and must be analyzed using three-phase load flow techniques. Against the above background, this paper proposes a three-phase WTGS model that can be applied to unbalanced distribution systems. The proposed method is based on the two-port network model, which has successfully been applied to a single-phase system [14]. Therefore, the main contributions of the present work are as shown: i) development of WTGS steady state model to be used in three-phase load flow analysis, and ii) modification and extension of the single-phase two-port network model so that it can facilitate threephase load flow analysis under unbalanced system conditions. Moreover, validation studies using 12-node and 19-node distribution systems are also presented and discussed in this paper. To be systematic, the paper is organized as: section 2 discusses the formulation of the three-phase distribution system load flow (DSLF) problem. Section 3 addresses the single-phase two-port network model of WTGS. Extension of the singlephase two-port network model to a three-phase two-port network model is given in section 4 . Section 5 discusses a study case where validation of the proposed method is presented and investigated. Finally, some essential conclusions of the paper are pointed out in section 6 .

\section{FORMULATION OF THREE-PHASE DSLF PROBLEM}

It can be shown that the formulation of three-phase load flow problem of unbalanced distribution system will have the form in (1):

$$
\left\{\left[\operatorname{diag}\left(V^{a b c}\right)\right]^{-1}\left(S_{G}^{a b c}-S_{L}^{a b c}\right)\right\}^{*}-Y^{a b c} V^{a b c}=0
$$

where $\boldsymbol{V}^{a b c}$ is vector of nodal voltage, $\boldsymbol{S}_{\boldsymbol{G}}{ }^{a b c}$ is vector of power entering the node, $\boldsymbol{S}_{\boldsymbol{L}}{ }^{a b c}$ is vector of power leaving the node, and $\boldsymbol{Y}^{a b c}$ is system admittance matrix.

For $n$-node distribution system, the formulations for $\boldsymbol{V}^{a b c}, \boldsymbol{S}_{\boldsymbol{G}}{ }^{a b c}, \boldsymbol{S}_{\boldsymbol{L}}{ }^{a b c}$ and $\boldsymbol{Y}^{a b c}$ are given by:

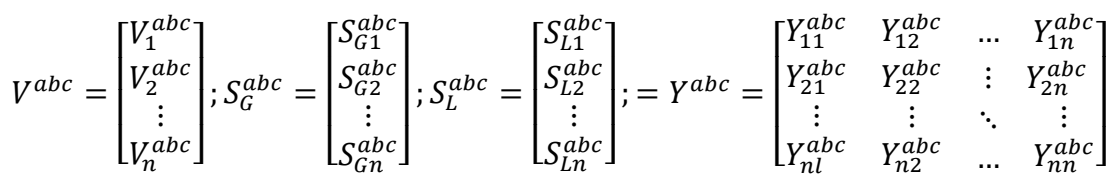

where:

$$
V_{i}^{a b c}=\left[\begin{array}{l}
V_{i}^{a} \\
V_{i}^{b} \\
V_{i}^{c}
\end{array}\right] ; S_{G i}^{a b c}=\left[\begin{array}{l}
S_{G i}^{a} \\
S_{G i}^{b} \\
S_{G i}^{c}
\end{array}\right] ; S_{L i}^{a b c}=\left[\begin{array}{l}
S_{L i}^{a} \\
S_{G i}^{b} \\
S_{L i}^{c}
\end{array}\right] ; Y_{i i}^{a b c}=\left[\begin{array}{ccc}
Y_{i i}^{a a} & Y_{i i}^{a b} & Y_{i i}^{a c} \\
Y_{i i}^{b a} & Y_{i i}^{b b} & Y_{i i}^{b c} \\
Y_{i i}^{c a} & Y_{i i}^{c b} & Y_{i i}^{c c}
\end{array}\right] ; Y_{i j}^{a b c}=\left[\begin{array}{ccc}
Y_{i j}^{a a} & Y_{i j}^{a b} & Y_{i j}^{a c} \\
Y_{i j}^{b a} & Y_{i j}^{b b} & Y_{i j}^{b c} \\
Y_{i j}^{c a} & Y_{i j}^{c b} & Y_{i j}^{c c}
\end{array}\right]
$$

It can be seen that (1) is a set of nonlinear equations which has to be solved in the load flow analysis to evaluate the steady state condition of the distribution system. As it is nonlinear, iterative techniques, for examples: Newton-Raphson or trust-region methods [22], [23], can be used to find the solution to the set of equations.

Bulletin of Electr Eng \& Inf, Vol. 11, No. 1, February 2022: 11-19 


\section{TWO-PORT NETWORK MODEL OF WTGS}

\subsection{WTGS structure and two-port network}

A fixed-speed WTGS connected to bus $k$ of an electric power distribution system is shown in Figure 1. In fixed-speed WTGS, a squirrel cage induction generator (SCIG) is usually used to convert the turbine mechanical power to electrical power. In Figure 1, $S_{g}$ is WTGS electrical power output and $P_{m}$ is turbine mechanical power input. Steady state equivalent circuits of the SCIG is given in Figures 2(a) and 2(b) [3]-[6]. In Figure 2(a), $R_{S}$ and $X_{S}$ are stator resistance and reactance, $R_{R}$ and $X_{R}$ are are rotor resistance and reactance, $R_{c}$ and $X_{m}$ are core resistance and reactance, $V_{S}$ and $I_{S}$ are stator voltage and current, $V_{R}$ and $I_{R}$ are rotor voltage and current, and $s$ is induction generator slip. Also the impedance values of $Z_{S}, Z_{R}$ and $Z_{M}$ in Figure 2(b) can be calculated using:

$$
\begin{aligned}
& Z_{S}=R_{S}+j X_{S} \\
& Z_{R}=R_{R}+j X_{R} \\
& Z_{M}=j R_{c} X_{m} /\left(R_{c}+j X_{m}\right)
\end{aligned}
$$

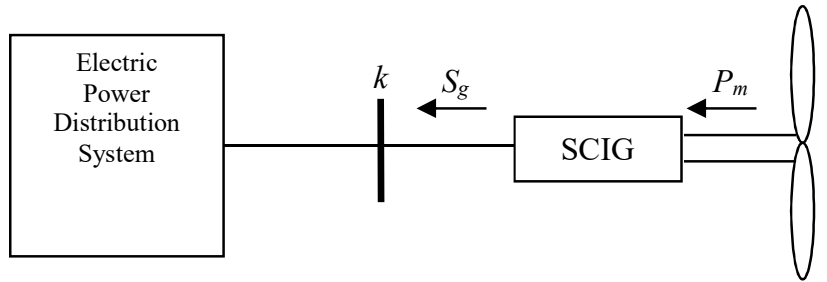

Figure 1. WTGS connected to distribution system

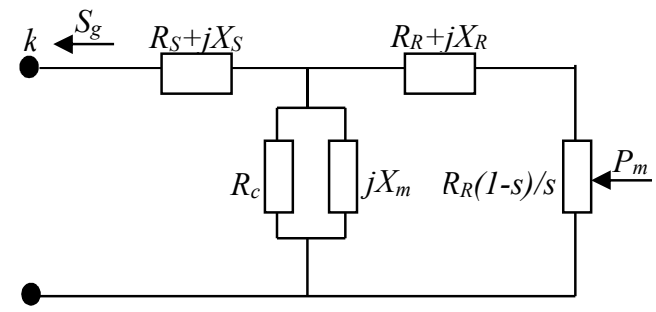

(a)

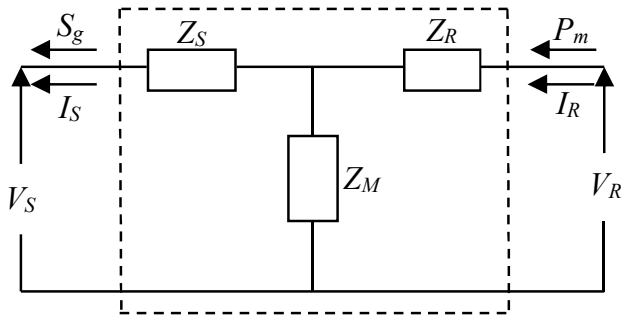

(b)

Figure 2. Steady state equivalent circuit of SCIG (a) in terms of resistances and reactances and (b) in terms of impedances

Figure 3 shows a general two-port network containing passive impedances/admittances [14]. In Figure 3, $A, B, C$ and $D$ are the general two-port network constants. The values of these constants depend on the impedances/admittances of the network components. For the two-port network in Figure 3, it can be shown that the voltage/current relationships are of the forms:

$$
\begin{aligned}
& V_{R}=\frac{1}{A D-B C}\left(D V_{S}+B I_{S}\right) \\
& I_{R}=\frac{1}{A D-B C}\left(C V_{S}+A I_{S}\right)
\end{aligned}
$$

The two-port network model of WTGS is obtained by viewing the SCIG equivalent circuit in Figure 2(b) as a two-port network. For the equivalent circuit in Figure 2(b), the formulas for the $A, B, C$ and $D$ constants of the two-port network will have the following forms [14]:

$$
A=1+Z_{S} / Z_{M}
$$




$$
\begin{aligned}
& B=Z_{S}+Z_{R}+Z_{S} Z_{R} / Z_{M} \\
& C=1 / Z_{M} \\
& D=1+Z_{R} / Z_{M}
\end{aligned}
$$

where $Z_{S}, Z_{R}$ and $Z_{M}$ are calculated using (4). Development of the WTGS model using the two-port network theory will be discussed in the next section.

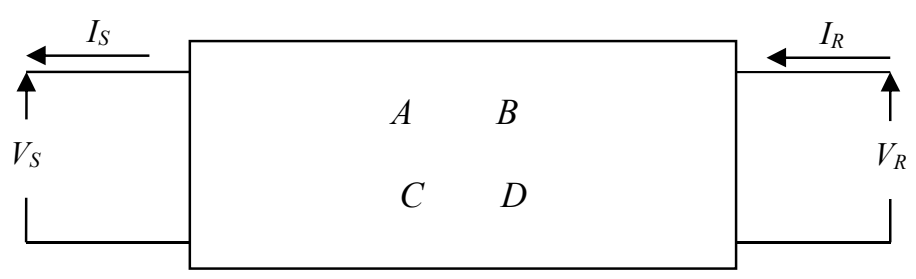

Figure 3. General two-port network

\subsection{Two-port network model of WTGS}

Derivation of the two-port network model of WTGS is based on WTGS power formulas, i.e. WTGS electrical power output and turbine mechanical power input. By looking at Figure 2, the formulas for WTGS electrical power output $\left(S_{g}\right)$ and turbine mechanical power input $\left(P_{m}\right)$ can be written as:

$$
S_{g}=P_{g}+j Q_{g}=V_{S} I_{S}^{*}
$$

and:

$$
P_{m}=V_{R} I_{R}^{*}
$$

Substituting (5) into (7b) gives:

$$
P_{m}=\left[\frac{1}{A D-B C}\left(D V_{S}+B I_{S}\right)\right]\left[\frac{1}{A D_{-} B C}\left(C V_{S}+A I_{S}\right)\right]^{*}
$$

On using (7a) in (8) and rearranging, can be obtained:

$$
P_{m}=Z_{1} V_{v}+Z_{2} S_{g}+Z_{3} S_{g}^{*}+Z_{4} S_{v}
$$

where:

$$
\begin{aligned}
& Z_{1}=\frac{D C^{*}}{(A D-B D)(A D-B C)^{*}} ; Z_{2}=\frac{D A^{*}}{(A D-B C)(A D-B C)^{*}} ; V_{v}=V_{v} V_{s}^{*} \\
& Z_{3}=\frac{B C^{*}}{(A C-B C)(A D-B C)^{*}} ; Z_{4}=\frac{B A^{*}}{(A D-B C)(A D-B C)^{*}} ; S_{v}=\frac{S_{g} S_{g}^{*}}{V_{s} V_{s}^{*}}
\end{aligned}
$$

As shown in (9) is the steady state model of WTGS for single-phase load flow analysis. Extension of the model to three-phase load flow analysis will be discussed in the next section.

\section{THREE-PHASE TWO-PORT NETWORK MODEL OF WTGS}

For three-phase system, in (9) can be modified to become:

$$
P_{m}^{a b c}=Z_{1}^{a b c} V_{v}^{a b c}+Z_{2}^{a b c} S_{g}^{a b c}+Z_{g}^{a b c}\left(S_{g}^{a b c}\right)^{*}+Z_{4}^{a b c} S_{v}^{a b c}
$$

where: 


$$
\boldsymbol{P}_{m}^{a b c}=\left[\begin{array}{l}
P_{m} / 3 \\
P_{m} / 3 \\
P_{m} / 3
\end{array}\right] ; \boldsymbol{S}_{g}^{a b c}=\left[\begin{array}{l}
S_{g}^{a} \\
S_{g}^{b} \\
S_{g}^{c}
\end{array}\right] ; \boldsymbol{V}_{v}^{a b c}=\left[\begin{array}{l}
V_{s}^{a}\left(V_{s}^{a}\right)^{*} \\
V_{s}^{b}\left(V_{s}^{b}\right)^{*} \\
V_{s}^{b}\left(V_{s}^{b}\right)^{*}
\end{array}\right] ; \boldsymbol{S}_{v}^{a b c}=\left[\begin{array}{l}
\frac{s_{g}^{a}\left(S_{g}^{a}\right)^{*}}{V_{s}^{a}\left(V_{s}^{a}\right)^{*}} \\
\frac{s_{g}^{b}\left(s_{g}^{b}\right)^{*}}{V_{s}^{b}\left(V_{s}^{b}\right)^{*}} \\
\frac{s_{g}^{c}\left(S_{g}^{c}\right)^{*}}{V_{s}^{c}\left(V_{s}^{c}\right)^{*}}
\end{array}\right] ; \boldsymbol{Z}_{i}^{a b c}=\left[\begin{array}{ccc}
Z_{i}^{a} & 0 & 0 \\
0 & Z_{i}^{b} & 0 \\
0 & 0 & Z_{i}^{c}
\end{array}\right] \text { (12) }
$$

Diagonal elements of $\boldsymbol{Z}_{i}^{a b c}$ matrix in (12) will have the following forms:

$$
\begin{aligned}
& Z_{1}^{p}=\frac{D^{p} C^{p *}}{\left(A^{p} D^{p}-B^{p} C^{p}\right)\left(A^{p} D^{p}-B^{p} C^{p} C\right)^{*}} ; Z_{2}^{p}=\frac{D^{p} A^{p *}}{\left(A^{p} D^{p}-B^{p} C^{p}\right)\left(A^{p} D^{p}-B^{p} C^{p} C\right)^{*}} \\
& Z_{3}^{p}=\frac{{ }_{B}^{p} C^{p *}}{\left(A^{p} D^{p}-B^{p} C^{p}\right)\left(A^{p} D^{p}-B^{p} C^{p} C\right)^{*}} ; Z_{4}^{p}=\frac{{ }_{B}^{p} A^{p *}}{\left(A^{p} D^{p}-B^{p} C^{p}\right)\left(A^{p} D^{p}-B^{p} C^{p} C\right)^{*}}
\end{aligned}
$$

where: $p=a, b, c$; and $A^{p}, B^{p}, C^{p}$ dan $D^{p}$ are calculated using:

$$
\begin{aligned}
& A^{p}=1+Z_{S}^{p} / Z_{M}^{p} \\
& B^{p}=Z_{S}^{p}+Z_{R}^{p}+Z_{S}^{p} Z_{R}^{p} / Z_{M}^{p} \\
& C^{p}=1 / Z_{M}^{p} \\
& D^{p}=1+Z_{R}^{p} / Z_{M}^{p}
\end{aligned}
$$

Based on (4), the formulations for $Z_{S}^{p}, Z_{R}^{p}$, and $Z_{M}^{p}$ in (14) are:

$$
\begin{aligned}
& Z_{S}^{p}=R_{s}^{p}+j X_{s}^{p} \\
& Z_{R}^{p}=R_{R}^{p}+j X_{R}^{p} \\
& Z_{M}^{p}=j R_{c}^{p} X_{m}^{p} /\left(R_{c}^{p}+j X_{m}^{p}\right)
\end{aligned}
$$

To carry out three-phase load flow analysis for distribution system embedded with WTGS, the first step is to rearrange (11) to the following form:

$$
\boldsymbol{P}_{m}^{a b c}-\boldsymbol{Z}_{1}^{a b c} \boldsymbol{V}_{v}^{a b c}-\boldsymbol{Z}_{2}^{a b c} \boldsymbol{S}_{g}^{a b c}-\boldsymbol{Z}_{3}^{a b c}\left(\boldsymbol{S}_{g}^{a b c}\right)^{*}-\boldsymbol{Z}_{4}^{a b c} \boldsymbol{S}_{v}^{a b c}=\mathbf{0}
$$

Then, for the system nodes containing WTGS, (16) is combined with (1). These combined equations, together with the remaining nodal equations, are solved simultaneously. Table 1 shows all of the quantities and equations in the complete formulation of a three-phase load flow problem for an electric power distribution system containing WTGS.

It should be noted that in (16), the voltage at WTGS node or WTGS terminal is also the voltage of SCIG stator, and the power injection at WTGS node is also the power output of WTGS, therefore:

$$
\begin{aligned}
& V_{j}^{a b c}=\boldsymbol{V}_{s}^{a b c} \\
& \boldsymbol{S}_{G j}^{a b c}=\boldsymbol{S}_{g}^{a b c}
\end{aligned}
$$

where $j$ is the node where the WTGS is connected.

Table 1. Known and unknown variables in three-phase DSLF formulation for system with WTGS

\begin{tabular}{cccc}
\hline Node & Equation & Known variable & Unknown variable \\
\hline Substation & $(1)$ & $Y^{a b c} ; S_{L}^{a b c} ; V^{a b c}$ & $S_{G}^{a b c}$ \\
Load & $(1)$ & $Y^{a b c} ; S_{L}^{a b c} ; S_{G}^{a b c}$ & $V^{a b c}$ \\
WTGS & $(1) \&(16)$ & $Y^{a b c} ; S_{L}^{a b c} ; P_{m}^{a b c} ; Z_{S}^{p} ; Z_{R}^{p} ; Z_{M}^{p}$ & $V^{a b c} ; S_{g}^{a b c}$ \\
\hline
\end{tabular}

$\overline{\text { Two-port network model of wind turbine generator for three-phase unbalanced DSLF analysis (Rudy Gianto) }}$ 


\section{CASE STUDY}

\subsection{Test system}

In this section, application of the proposed method in DSLF analysis is investigated. The test systems that are used in the investigation are described as shown in:

- $\quad$ System 1 is an $11 \mathrm{kV}$ distribution network with the total three-phase load of 4,305 kW and 1,215 kVAR [22]. Single line diagram of this 12-node balanced distribution system is shown in Figure 4 . Since the system is balanced, it can actually be analysed using single-phase approach. However, to validate the proposed method, three-phase approach will be used instead. Tables 2 and 3 show the data of system 1 . WTGS with power rating of $3,000 \mathrm{~kW}$ is assumed to be connected to node 12 .

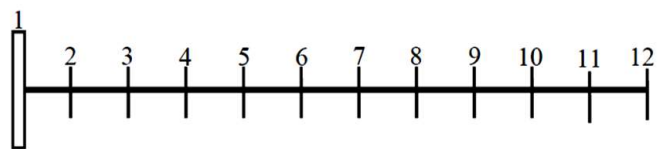

Figure 4. System 1

Table 2. Data of system 1

\begin{tabular}{ccccccc}
\hline Line No. & Sending bus & Receiving bus & $R^{*}$ & $X^{*}$ & $P_{L}{ }^{* *}$ & $Q_{L}{ }^{* *}$ \\
\hline 1 & 1 & 2 & 1.093 & 0.455 & 60 & 60 \\
2 & 2 & 3 & 1.184 & 0.494 & 140 & 30 \\
3 & 3 & 4 & 2.095 & 0.873 & 155 & 55 \\
4 & 4 & 5 & 3.188 & 1.329 & 130 & 30 \\
5 & 5 & 6 & 1.093 & 0.455 & 120 & 15 \\
6 & 6 & 7 & 1.002 & 0.417 & 155 & 55 \\
7 & 7 & 8 & 4.403 & 1.215 & 145 & 45 \\
8 & 8 & 9 & 5.642 & 1.597 & 140 & 40 \\
9 & 9 & 10 & 2.890 & 0.818 & 135 & 30 \\
10 & 10 & 11 & 1.514 & 0.428 & 140 & 30 \\
11 & 11 & 12 & 1.238 & 0.351 & 115 & 15 \\
\hline *Line resistance/reactance in ohm/phase
\end{tabular}

*Line resistance/reactance in ohm/phase

**Load connected to receiving bus in $\mathrm{kW}$ and $\mathrm{kVAR}$ (perphase)

Table 3. WTGS induction generator data for system 1

\begin{tabular}{cc}
\hline Parameter & Resistance/reactance value $(\mathrm{Ohm})$ \\
\hline Stator circuit & $R_{s}{ }^{a=} R_{s}{ }^{b}=R_{s}{ }^{c}=1.21$ \\
& $X_{s}^{a=} X_{s}^{b}=X_{s}{ }^{c}=6.05$ \\
Rotor circuit & $R_{r}^{a=} R_{r}^{b}=R_{r}{ }^{c}=1.21$ \\
& $X_{r}^{a=} X_{r}^{b}=X_{r}^{c}=6.05$ \\
Magnetic core circuit & $R_{c}{ }^{a=} R_{c}^{b}=R_{c}{ }^{c}=12,100$ \\
& $X_{m}{ }^{a=} X_{m}{ }^{b}=X_{m}{ }^{c}=605$ \\
\hline
\end{tabular}

- System 2 is a 19-node unbalanced distribution system adopted from [24], [25]. Single line diagram of the system is shown in Figure 5. It is an $11 \mathrm{kV}$ distribution network with the total load of $442.75 \mathrm{~kW}$ and 152.45 kVAR (Phase-a: $151.06 \mathrm{~kW}$ and 52.66 kVAR; Phase-b: $143.07 \mathrm{~kW}$ and $48.45 \mathrm{kVAR}$; Phase-c: $148.62 \mathrm{~kW}$ and $51.34 \mathrm{kVAR}$. The system line and load data can be found in Tables 4 dan 5 . WTGS with power rating of $300 \mathrm{~kW}$ is assumed to be connected to node 19. Data of the WTGS induction generator is given in Table 6 .

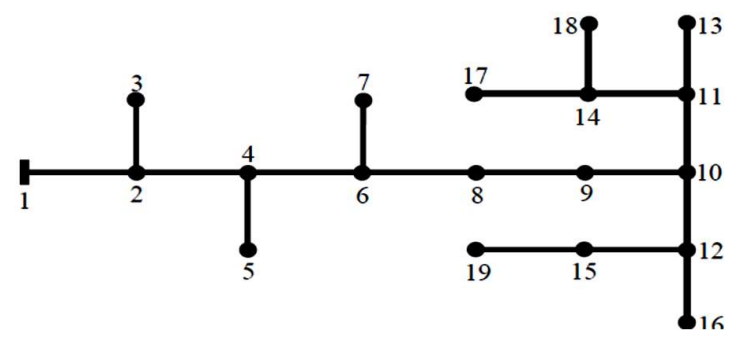

Figure 5. System 2 
Table 4. Test system line data

\begin{tabular}{cccc}
\hline No. & Line & Self impedance $(\mathrm{Ohm})$ & Mutual impedance $(\mathrm{Ohm})$ \\
\hline 1 & $1-2$ & $3.0 \times(1.56090+\mathrm{j} 0.67155)$ & $3.0 \times(0.52030+\mathrm{j} 0.22385)$ \\
2 & $2-3$ & $5.0 \times(1.56090+\mathrm{j} 0.67155)$ & $5.0 \times(0.52030+\mathrm{j} 0.22385)$ \\
3 & $2-4$ & $1.5 \times(1.56090+\mathrm{j} 0.67155)$ & $1.5 \times(0.52030+\mathrm{j} 0.22385)$ \\
4 & $4-5$ & $1.5 \times(1.56090+\mathrm{j} 0.67155)$ & $1.5 \times(0.52030+\mathrm{j} 0.22385)$ \\
5 & $4-6$ & $1.0 \times(1.56090+\mathrm{j} 0.67155)$ & $1.0 \times(0.52030+\mathrm{j} 0.22385)$ \\
6 & $6-7$ & $2.0 \times(1.56090+\mathrm{j} 0.67155)$ & $2.0 \times(0.52030+\mathrm{j} 0.22385)$ \\
7 & $6-8$ & $2.5 \times(1.56090+\mathrm{j} 0.67155)$ & $2.5 \times(0.52030+\mathrm{j} 0.22385)$ \\
8 & $8-9$ & $3.0 \times(1.56090+\mathrm{j} 0.67155)$ & $3.0 \times(0.52030+\mathrm{j} 0.22385)$ \\
9 & $9-10$ & $5.0 \times(1.56090+\mathrm{j} 0.67155)$ & $5.0 \times(0.52030+\mathrm{j} 0.22385)$ \\
10 & $10-11$ & $1.5 \times(1.56090+\mathrm{j} 0.67155)$ & $1.5 \times(0.52030+\mathrm{j} 0.22385)$ \\
11 & $10-12$ & $1.5 \times(1.56090+\mathrm{j} 0.67155)$ & $1.5 \times(0.52030+\mathrm{j} 0.22385)$ \\
12 & $11-13$ & $5.0 \times(1.56090+\mathrm{j} 0.67155)$ & $5.0 \times(0.52030+\mathrm{j} 0.22385)$ \\
13 & $11-14$ & $1.0 \times(1.56090+\mathrm{j} 0.67155)$ & $1.0 \times(0.52030+\mathrm{j} 0.22385)$ \\
14 & $12-15$ & $5.0 \times(1.56090+\mathrm{j} 0.67155)$ & $5.0 \times(0.52030+\mathrm{j} 0.22385)$ \\
15 & $12-16$ & $6.0 \times(1.56090+\mathrm{j} 0.67155)$ & $6.0 \times(0.52030+\mathrm{j} 0.22385)$ \\
16 & $14-17$ & $3.5 \times(1.56090+\mathrm{j} 0.67155)$ & $3.5 \times(0.52030+\mathrm{j} 0.22385)$ \\
17 & $14-18$ & $4.0 \times(1.56090+\mathrm{j} 0.67155)$ & $4.0 \times(0.52030+\mathrm{j} 0.22385)$ \\
18 & $15-19$ & $4.0 \times(1.56090+\mathrm{j} 0.67155)$ & $4.0 \times(0.52030+\mathrm{j} 0.22385)$ \\
\hline
\end{tabular}

Table 5. Test system load data

\begin{tabular}{ccccccc}
\hline \multirow{2}{*}{ Node } & \multicolumn{2}{c}{ Phase-a } & \multicolumn{2}{c}{ Phase-b } & \multicolumn{2}{c}{ Phase-c } \\
& $\mathrm{P}(\mathrm{kW})$ & $\mathrm{Q}(\mathrm{kVAR})$ & $\mathrm{P}(\mathrm{kW})$ & $\mathrm{Q}(\mathrm{kVAR})$ & $\mathrm{P}(\mathrm{kW})$ & $\mathrm{Q}(\mathrm{kVAR})$ \\
\hline 1 & 0 & 0 & 0 & 0 & 0 & 0 \\
2 & 10.38 & 5.01 & 5.19 & 2.52 & 10.38 & 5.01 \\
3 & 11.01 & 5.34 & 5.19 & 2.52 & 9.72 & 4.71 \\
4 & 4.05 & 1.95 & 5.67 & 2.76 & 6.48 & 3.15 \\
5 & 6.48 & 3.15 & 5.19 & 2.52 & 4.53 & 2.19 \\
6 & 4.20 & 2.04 & 3.09 & 1.50 & 2.91 & 1.41 \\
7 & 9.72 & 4.71 & 8.10 & 3.93 & 8.10 & 3.93 \\
8 & 7.44 & 3.60 & 5.34 & 2.58 & 3.39 & 1.65 \\
9 & 12.30 & 5.97 & 14.91 & 7.23 & 13.29 & 6.42 \\
10 & 3.39 & 1.65 & 4.20 & 2.04 & 2.58 & 1.26 \\
11 & 7.44 & 3.60 & 7.44 & 3.60 & 11.01 & 5.34 \\
12 & 9.72 & 4.71 & 8.10 & 3.93 & 8.10 & 3.93 \\
13 & 4.38 & 2.13 & 5.34 & 2.58 & 6.48 & 3.15 \\
14 & 3.09 & 1.50 & 3.09 & 1.50 & 4.05 & 1.95 \\
15 & 14.38 & 2.13 & 14.86 & 2.34 & 16.96 & 3.36 \\
16 & 17.77 & 3.78 & 20.38 & 5.01 & 17.77 & 3.78 \\
17 & 16.48 & 3.15 & 14.86 & 2.34 & 14.86 & 2.34 \\
18 & 15.34 & 2.58 & 15.34 & 2.58 & 15.52 & 2.67 \\
19 & 18.76 & 4.23 & 20.05 & 4.86 & 17.14 & 3.45 \\
\hline
\end{tabular}

Table 6. WTGS induction generator data for system 2

\begin{tabular}{cc}
\hline Parameter & Resistance/reactance value $(\mathrm{Ohm})$ \\
\hline Stator circuit & $R_{s}^{a=} R_{s}^{b}=R_{s}^{c}=0.080667$ \\
& $X_{s}^{a=} X_{s}^{b}=X_{s}^{c}=0.403333$ \\
Rotor circuit & $R_{r}^{a=} R_{r}^{b}=R_{r}^{c}=0.080667$ \\
& $X_{r}^{a=} X_{r}^{b}=X_{r}^{c}=0.403333$ \\
Magnetic core circuit & $R_{c}{ }^{a=} R_{c}^{b}=R_{c}^{c}=20166.6665$ \\
& $X_{m}{ }^{a=} X_{m}^{b}=X_{m}^{c}=1008.3335$ \\
\hline
\end{tabular}

\subsection{Results and discussion (system 1)}

Results of the load flow calculation of system 1 are given in Tables 7 and 8. WTGS model, as proposed in section 4 , is used in the calculation. It is to be noted that since the system is balanced, a singlephase approach such as the multiple-node model proposed in [3]-[5] can also be applied to analyze the system. For the purpose of comparison, results obtained by the multiple-node model are also given in the present work and are shown in Table 9. It can be seen that the results of the proposed method (Table 7 and Table 8) and those of the multiple-node method (Table 9) are in exact agreement, which indicates the validity of the method proposed. 
Table 7. WTGS terminal voltage magnitude (system 1)

\begin{tabular}{cccc}
\hline$P_{m}(\mathrm{~kW})$ & Phase-a $(\mathrm{kV})$ & Phase-b $(\mathrm{kV})$ & Phase-c $(\mathrm{kV})$ \\
\hline 300 & 9.86 & 9.86 & 9.86 \\
600 & 10.13 & 10.13 & 10.13 \\
900 & 10.38 & 10.38 & 10.38 \\
1200 & 10.62 & 10.62 & 10.62 \\
1500 & 10.84 & 10.84 & 10.84 \\
1800 & 11.05 & 11.05 & 11.05 \\
2100 & 11.25 & 11.25 & 11.25 \\
2400 & 11.44 & 11.44 & 11.44 \\
2700 & 11.62 & 11.62 & 11.62 \\
3000 & 11.80 & 11.80 & 11.80 \\
\hline
\end{tabular}

Table 8. Output power of WTGS (system 1)

\begin{tabular}{cccc}
\hline$P_{m}(\mathrm{~kW})$ & Phase-a (kW, kVAR) & Phase-b (kW, kVAR) & Phase-c (kW, kVAR) \\
\hline 300 & $91.55-\mathrm{j} 160.67$ & $91.55-\mathrm{j} 160.67$ & $91.55-\mathrm{j} 160.67$ \\
600 & $190.39-\mathrm{j} 173.26$ & $190.39-\mathrm{j} 173.26$ & $190.39-\mathrm{j} 173.26$ \\
900 & $288.87-\mathrm{j} 187.36$ & $288.87-\mathrm{j} 187.36$ & $288.87-\mathrm{j} 187.36$ \\
1200 & $387.03-\mathrm{j} 202.79$ & $387.03-\mathrm{j} 202.79$ & $387.03-\mathrm{j} 202.79$ \\
1500 & $484.91-\mathrm{j} 219.38$ & $484.91-\mathrm{j} 219.38$ & $484.91-\mathrm{j} 219.38$ \\
1800 & $582.53-\mathrm{j} 237.05$ & $582.53-\mathrm{j} 237.05$ & $582.53-\mathrm{j} 237.05$ \\
2100 & $679.93-\mathrm{j} 255.68$ & $679.93-\mathrm{j} 255.68$ & $679.93-\mathrm{j} 255.68$ \\
2400 & $777.11-\mathrm{j} 275.20$ & $777.11-\mathrm{j} 275.20$ & $777.11-\mathrm{j} 275.20$ \\
2700 & $874.10-\mathrm{j} 295.56$ & $874.10-\mathrm{j} 295.56$ & $874.10-\mathrm{j} 295.56$ \\
3000 & $970.90-\mathrm{j} 316.69$ & $970.90-\mathrm{j} 316.69$ & $970.90-\mathrm{j} 316.69$ \\
\hline
\end{tabular}

Table 9. Results obtained by multiple-node model [3]-[5]

\begin{tabular}{ccc}
\hline$P_{m}(\mathrm{~kW})$ & WTGS voltage $(\mathrm{kV})$ & WTGS output $(\mathrm{kW}, \mathrm{kVAR})$ \\
\hline 300 & 9.86 & $91.55-\mathrm{j} 160.67$ \\
600 & 10.13 & $190.39-\mathrm{j} 173.26$ \\
900 & 10.38 & $288.87-\mathrm{j} 187.36$ \\
1200 & 10.62 & $387.03-\mathrm{j} 202.79$ \\
1500 & 10.84 & $484.91-\mathrm{j} 219.38$ \\
1800 & 11.05 & $582.53-\mathrm{j} 237.05$ \\
2100 & 11.25 & $679.93-\mathrm{j} 255.68$ \\
2400 & 11.44 & $777.11-\mathrm{j} 275.20$ \\
2700 & 11.62 & $874.10-\mathrm{j} 295.56$ \\
3000 & 11.80 & $970.90-\mathrm{j} 316.69$ \\
\hline
\end{tabular}

\subsection{Results and discussion (system 2)}

Tables 10-13 show the results of load flow analysis for the 19-node distribution system in Figure 5. To make a better observation, the results are also presented in graphical forms (see Figures 6-9). Due to the system unbalance, it can be seen from the tables that the electrical quantities in the three phases are not the same. Table 10 shows that with the increase in turbine mechanical power and WTGS output, the voltage profile improves (see also Figure 6). On the other hand, results in Table 11 show that as the turbine mechanical power input increases, the active power output of the WTGS also increases linearly (see also Figure 7). However, the WTGS power output is slightly smaller than the turbine mechanical power due to power loss in the WTGS. Table 11 also shows that the reactive power output of WTGS is negative, which means that the WTGS absorbs reactive power from the system. This reactive power is used by the WTGS induction generator for the purposes of magnetizing the core circuit. Figure 8 shows the variation of WTGS reactive-power demand against turbine mechanical power. It can be seen that the relationship is also linear, which indicates that the demand for reactive power increases as the WTGS active power output increases.

Table 10. WTGS terminal voltage magnitude (system 2)

\begin{tabular}{cccc}
\hline$P_{m}(\mathrm{~kW})$ & Phase-a $(\mathrm{kV})$ & Phase-b $(\mathrm{kV})$ & Phase-c $(\mathrm{kV})$ \\
\hline 30 & 10.0966 & 10.0749 & 10.0838 \\
60 & 10.1797 & 10.1587 & 10.1674 \\
90 & 10.2615 & 10.2410 & 10.2494 \\
120 & 10.3417 & 10.3219 & 10.3299 \\
150 & 10.4205 & 10.4012 & 10.4090 \\
180 & 10.4981 & 10.4792 & 10.4869 \\
210 & 10.5744 & 10.5559 & 10.5633 \\
240 & 10.6494 & 10.6315 & 10.6387 \\
270 & 10.7234 & 10.7059 & 10.7128 \\
300 & 10.7962 & 10.7790 & 10.7858 \\
\hline
\end{tabular}

Bulletin of Electr Eng \& Inf, Vol. 11, No. 1, February 2022: 11-19 
Table 11. Output power of WTGS (system 2)

\begin{tabular}{ccccc}
\hline$P_{m}(\mathrm{~kW})$ & Phase-a $(\mathrm{kW}, \mathrm{kVAR})$ & Phase-b $(\mathrm{kW}, \mathrm{kVAR})$ & Phase-c $(\mathrm{kW}, \mathrm{kVAR})$ & 3-Phase $(\mathrm{kW}, \mathrm{kVAR})$ \\
\hline 30 & $8.31-\mathrm{j} 33.69$ & $8.32-\mathrm{j} 33.55$ & $8.32-\mathrm{j} 33.60$ & $24.95-\mathrm{j} 100.84$ \\
60 & $18.28-\mathrm{j} 34.25$ & $18.29-\mathrm{j} 34.11$ & $18.29-\mathrm{j} 34.17$ & $54.86-\mathrm{j} 102.53$ \\
90 & $28.25-\mathrm{j} 34.82$ & $28.26-\mathrm{j} 34.68$ & $28.26-\mathrm{j} 34.74$ & $84.77-\mathrm{j} 104.24$ \\
120 & $38.22-\mathrm{j} 35.38$ & $38.23-\mathrm{j} 35.25$ & $38.23-\mathrm{j} 35.30$ & $114.68-\mathrm{j} 105.93$ \\
150 & $48.19-\mathrm{j} 35.94$ & $48.20-\mathrm{j} 35.81$ & $48.20-\mathrm{j} 35.86$ & $144.59-\mathrm{j} 107.61$ \\
180 & $58.16-\mathrm{j} 36.50$ & $58.17-\mathrm{j} 36.37$ & $58.16-\mathrm{j} 36.43$ & $174.49-\mathrm{j} 109.30$ \\
210 & $68.13-\mathrm{j} 37.06$ & $68.14-\mathrm{j} 36.94$ & $68.13-\mathrm{j} 36.99$ & $204.40-\mathrm{j} 110.99$ \\
240 & $78.10-\mathrm{j} 37.62$ & $78.10-\mathrm{j} 37.50$ & $78.10-\mathrm{j} 37.55$ & $234.30-\mathrm{j} 112.67$ \\
270 & $88.06-\mathrm{j} 38.18$ & $88.07-\mathrm{j} 38.06$ & $88.07-\mathrm{j} 38.10$ & $264.20 \mathrm{j} 114.34$ \\
300 & $98.03-\mathrm{j} 38.74$ & $98.04-\mathrm{j} 38.61$ & $98.03-\mathrm{j} 38.66$ & $294.10-\mathrm{j} 116.01$ \\
\hline
\end{tabular}

Table 12. Substation power (system 2)

\begin{tabular}{ccccc}
\hline$P_{m}(\mathrm{~kW})$ & Phase-a $(\mathrm{kW}, \mathrm{kVAR})$ & Phase-b $(\mathrm{kW}, \mathrm{kVAR})$ & Phase-c $(\mathrm{kW}, \mathrm{kVAR})$ & 3-Phase $(\mathrm{kW}, \mathrm{kVAR})$ \\
\hline 30 & $179.69+\mathrm{j} 99.95$ & $169.82+\mathrm{j} 94.93$ & $176.84+\mathrm{j} 98.43$ & $526.35+\mathrm{j} 293.32$ \\
60 & $168.40+\mathrm{j} 99.95$ & $158.49+\mathrm{j} 94.92$ & $165.52+\mathrm{j} 98.41$ & $492.41+\mathrm{j} 293.28$ \\
90 & $157.30+\mathrm{j} 100.03$ & $147.35+\mathrm{j} 94.99$ & $154.40+\mathrm{j} 98.48$ & $459.05+\mathrm{j} 293.50$ \\
120 & $146.38+\mathrm{j} 100.19$ & $136.40+\mathrm{j} 95.14$ & $143.46+\mathrm{j} 98.62$ & $426.24+\mathrm{j} 293.95$ \\
150 & $135.64+\mathrm{j} 100.42$ & $125.62+\mathrm{j} 95.36$ & $132.70+\mathrm{j} 98.84$ & $393.96+\mathrm{j} 294.61$ \\
180 & $125.06+\mathrm{j} 100.72$ & $115.02+\mathrm{j} 95.66$ & $122.10+\mathrm{j} 99.12$ & $362.19+\mathrm{j} 295.50$ \\
210 & $114.65+\mathrm{j} 101.08$ & $104.58+\mathrm{j} 96.02$ & $111.67+\mathrm{j} 99.48$ & $330.90+\mathrm{j} 296.58$ \\
240 & $104.39+\mathrm{j} 101.52$ & $94.29+\mathrm{j} 96.45$ & $101.40+\mathrm{j} 99.90$ & $300.08+\mathrm{j} 297.87$ \\
270 & $94.28+\mathrm{j} 102.01$ & $84.15+\mathrm{j} 96.94$ & $91.27+\mathrm{j} 100.39$ & $269.70+\mathrm{j} 299.34$ \\
300 & $84.31+\mathrm{j} 102.57$ & $74.16+\mathrm{j} 97.49$ & $81.28+\mathrm{j} 100.93$ & $239.75+\mathrm{j} 300.99$ \\
\hline
\end{tabular}

Table 13. Distribution line loss (system 2)

\begin{tabular}{ccccc}
\hline$P_{m}(\mathrm{~kW})$ & Phase-a $(\mathrm{kW}, \mathrm{kVAR})$ & Phase-b $(\mathrm{kW}, \mathrm{kVAR})$ & Phase-c $(\mathrm{kW}, \mathrm{kVAR})$ & $3-P h a s e(\mathrm{~kW}, \mathrm{kVAR})$ \\
\hline 30 & $36.94+\mathrm{j} 13.60$ & $35.07+\mathrm{j} 12.93$ & $36.54+\mathrm{j} 13.49$ & $108.55+\mathrm{j} 40.02$ \\
60 & $35.62+\mathrm{j} 13.04$ & $33.71+\mathrm{j} 12.36$ & $35.19+\mathrm{j} 12.90$ & $104.52+\mathrm{j} 38.30$ \\
90 & $34.49+\mathrm{j} 12.55$ & $32.54+\mathrm{j} 11.86$ & $34.04+\mathrm{j} 12.40$ & $101.07+\mathrm{j} 36.81$ \\
120 & $33.54+\mathrm{j} 12.15$ & $31.56+\mathrm{j} 11.44$ & $33.07+\mathrm{j} 11.98$ & $98.17+\mathrm{j} 35.57$ \\
150 & $32.77+\mathrm{j} 11.82$ & $30.75+\mathrm{j} 11.10$ & $32.28+\mathrm{j} 11.64$ & $95.80+\mathrm{j} 34.56$ \\
180 & $32.16+\mathrm{j} 11.56$ & $30.12+\mathrm{j} 10.84$ & $31.64+\mathrm{j} 11.35$ & $93.92+\mathrm{j} 33.75$ \\
210 & $31.72+\mathrm{j} 11.36$ & $29.65+\mathrm{j} 10.63$ & $31.18+\mathrm{j} 11.15$ & $92.55+\mathrm{j} 33.14$ \\
240 & $31.43+\mathrm{j} 11.24$ & $29.32+\mathrm{j} 10.50$ & $30.88+\mathrm{j} 11.01$ & $91.63+\mathrm{j} 32.75$ \\
270 & $31.28+\mathrm{j} 11.17$ & $29.15+\mathrm{j} 10.43$ & $30.72+\mathrm{j} 10.95$ & $91.15+\mathrm{j} 32.55$ \\
300 & $31.28+\mathrm{j} 11.17$ & $29.13+\mathrm{j} 10.43$ & $30.69+\mathrm{j} 10.93$ & $91.10+\mathrm{j} 32.53$ \\
\hline
\end{tabular}

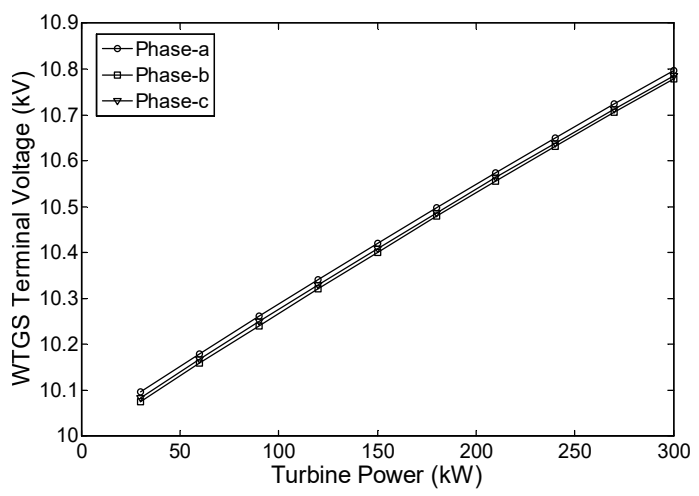

Figure 6. Variation of voltage magnitude

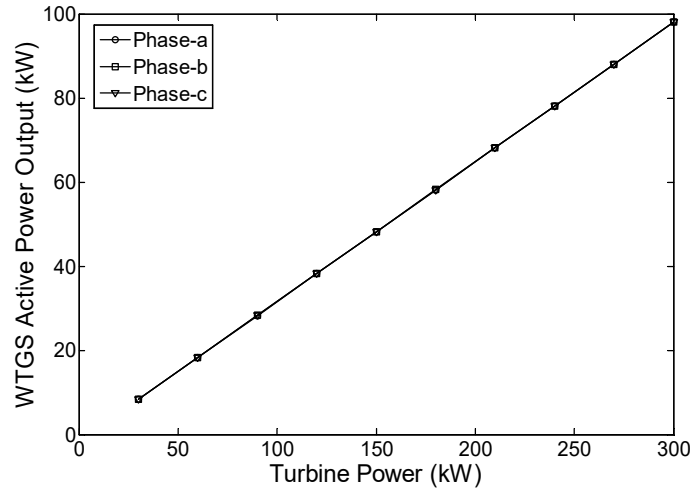

Figure 7. Variation of WTGS active power

Table 12 shows that with the WTGS installed in the system, besides the voltage profile improvement, another advantage is that the power supply from the distribution system substation can be reduced since some of the loads can be fed by the WTGS (see also Figure 9). Power supply from distribution system substation usually comes from the conventional generator with a non-renewable energy source (fossil fuel) that is not environmentally friendly. Moreover, as the WTGS active power output increases, the line power loss decreases (see Table 13). This line loss decrement is due to the voltage profile improvement as the WTGS active power output increases. The above results confirm the validity of the method proposed. 
Further validation can be obtained by examining the results where the substation output plus WTGS output is always equal to the total system load plus total line loss. It is to be noted that the line loss has been calculated based on the impedances and currents of the distribution lines.

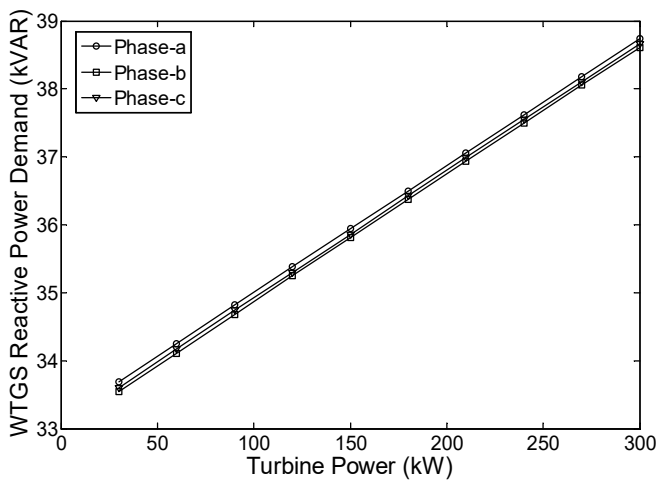

Figure 8. Variation of WTGS reactive power



Figure 9. Variation of substation power

\section{CONCLUSION}

Most of the previous WTGS models assumed that the system was balanced, and single-phase load flow approaches were used to analyze the system. However, electric power distribution systems are generally unbalanced and must be analyzed using three-phase load flow techniques. Therefore, the development of a three-phase model of all components of the electric power system (including WTGS) is very important so that the system can be analyzed and its performance can properly be evaluated. A simple method to incorporate WTGS in load flow analysis of a three-phase unbalanced distribution system has been proposed in this paper. The proposed method is based on a previously published single-phase two-port network model. In this paper, the single-phase two-port network model has been modified and extended so that it can be applied to three-phase systems. The model is then included in a three-phase load flow analysis of an unbalanced distribution network. An extensive case study has also been carried out in this paper. In the case study, the application of the proposed method to 12-node and 19-node distribution systems has been investigated. The investigation results confirm and verify the validity of the method proposed.

\section{ACKNOWLEDGEMENTS}

The authors would like to express special appreciation to the Ministry of Education, Culture, Research, and Technology (Kemendikbudristek Republik Indonesia) for funding the research reported in this paper.

\section{REFERENCES}

[1] J.-H. Teng, "Modelling distributed generations in three-phase distribution load flow," IET Generation, Transmission \& Distribution, vol. 2, no. 3, p. 330, 2008, doi: 10.1049/iet-gtd:20070165.

[2] S. Ammous, A. Oualha, and H. H. Abdallah, "A Study of the Problem of Load Flow in a Network Involving a Renewable Source of Energy," International Review on Modelling and Simulations (IREMOS), vol. 7, no. 6, p. 927, Dec. 2014, doi: 10.15866/iremos.v7i6.4574.

[3] M. H. Haque, "Evaluation of power flow solutions with fixed speed wind turbine generating systems," Energy Conversion and Management, vol. 79, pp. 511-518, Mar. 2014, doi: 10.1016/j.enconman.2013.12.049.

[4] J. Wang, C. Huang, and A. F. Zobaa, "Multiple-node Models of Asynchronous Wind Turbines in Wind Farm for Load Flow Analysis," Electric Power Components and Systems, vol. 44, no. 2, pp. 135-141, Jan. 2016, doi: 10.1080/15325008.2015.1102180.

[5] M. H. Haque, "Incorporation of fixed speed wind turbine generators in load flow analysis of distribution systems," International Journal of Renewable Energy Technology, vol. 6, no. 4, p. 317, 2015, doi: 10.1504/IJRET.2015.072099.

[6] A. Feijoo, "On PQ Models for Asynchronous Wind Turbines," IEEE Transactions on Power Systems, vol. 24, no. 4, pp. 18901891, Nov. 2009, doi: 10.1109/TPWRS.2009.2030243.

[7] D. Villanueva, J. L. Pazos, and A. Feijoo, "Probabilistic Load Flow Including Wind Power Generation," IEEE Transactions on Power Systems, vol. 26, no. 3, pp. 1659-1667, Aug. 2011, doi: 10.1109/TPWRS.2010.2096436.

[8] A. Feijoo, J. Luis Pazos, and D. Villanueva, "Conventional Asynchronous Wind Turbine Models Mathematical Expressions for the Load Flow Analysis," International Journal of Energy Engineering, vol. 3, no. 6, pp. 269-278, Dec. 2013, doi: 10.5963/IJEE0306008. 
[9] A. Feijoo and D. Villanueva, "A PQ Model for Asynchronous Machines Based on Rotor Voltage Calculation," IEEE Transactions on Energy Conversion, vol. 31, no. 2, pp. 813-814, Jun. 2016, doi: 10.1109/TEC.2016.2529502.

[10] A. Feijoo and D. Villanueva, "Correction to 'A PQ Model for Asynchronous Machines Based on Rotor Voltage Calculation' [Jun 16 813-814]," IEEE Transactions on Energy Conversion, vol. 31, no. 2, pp. 818-818, Jun. 2016, doi: 10.1109/TEC.2016.2557998.

[11] U. Eminoglu, "A New Model for Wind Turbine Systems," Electric Power Components and Systems, vol. 37, no. 10, pp. 11801193, Sep. 2009, doi: 10.1080/15325000902954060.

[12] U. Eminoglu, B. Dursun, and M. H. Hocaoglu, "Incorporation of a new wind turbine generating system model into distribution systems load flow analysis," Wind Energy, vol. 12, no. 4, pp. 375-390, May 2009, doi: 10.1002/we.299.

[13] L. M. Castro, C. R. Fuerte-Esquivel, and J. H. Tovar-Hernández, "A unified approach for the solution of power flows in electric power systems including wind farms," Electric Power Systems Research, vol. 81, no. 10, pp. 1859-1865, Oct. 2011, doi: 10.1016/j.epsr.2011.05.007.

[14] R. Gianto, K. H. Khwee, H. Priyatman, and M. Rajagukguk, "Two-port network model of fixed-speed wind turbine generator for distribution system load flow analysis," TELKOMNIKA (Telecommunication Computing Electronics and Control), vol. 17, no. 3, p. 1569, Jun. 2019, doi: 10.12928/telkomnika.v17i3.11866.

[15] R. Gianto, "Steady State Model of Wind Power Plant for Load Flow Study," in 2020 International Seminar on Intelligent Technology and Its Applications (ISITIA), Jul. 2020, pp. 119-122, doi: 10.1109/ISITIA49792.2020.9163687.

[16] R. Gianto and K. Hie Khwee, "A new T-circuit model of wind turbine generator for power system steady state studies," Bulletin of Electrical Engineering and Informatics, vol. 10, no. 2, pp. 550-558, Apr. 2021, doi: 10.11591/eei.v10i2.2306.

[17] M. Zhao, Z. Chen, and F. Blaabjerg, "Load flow analysis for variable speed offshore wind farms," IET Renewable Power Generation, vol. 3, no. 2, p. 120, 2009, doi: 10.1049/iet-rpg:20070094.

[18] S. S. K. V. and D. Thukaram, "Accurate modeling of doubly fed induction generator based wind farms in load flow analysis," Electric Power Systems Research, vol. 155, pp. 363-371, Feb. 2018, doi: 10.1016/j.epsr.2017.09.011.

[19] S. Li, "Power Flow Modeling to Doubly-Fed Induction Generators (DFIGs) Under Power Regulation," IEEE Transactions on Power Systems, vol. 28, no. 3, pp. 3292-3301, Aug. 2013, doi: 10.1109/TPWRS.2013.2251914.

[20] A. C.V.S. and S. S. K. V, "Enhanced modelling of doubly fed induction generator in load flow analysis of distribution systems," IET Renewable Power Generation, vol. 15, no. 5, pp. 980-989, Apr. 2021, doi: 10.1049/rpg2.12077.

[21] R. Gianto, "Steady-state model of DFIG-based wind power plant for load flow analysis," IET Renewable Power Generation, vol. 15 , no. 8, pp. 1724-1735, Jun. 2021, doi: 10.1049/rpg2.12141

[22] R. Gianto and K. Hie Khwee, "A New Method for Load Flow Solution of Electric Power Distribution System," International Review of Electrical Engineering (IREE), vol. 11, no. 5, p. 535, Oct. 2016, doi: 10.15866/iree.v1 1i5.9993.

[23] Y. Yuan, "Recent Advances in Numerical Methods for Nonlinear Equations," Numerical Algebra Control and Optimization, vol. 1, no. 1, pp. 15-34, 2011, doi: 10.3934/naco.2011.1.15.

[24] P. U. Reddy, S. Sivanagaraju, Prabandhamkam, and Sangameswararaju, "Power Flow Analysis of Three Phase Unbalanced Distribution System," International Journal of Advances in Engineering and Technology, vol. 3, no. 1, p. 514, 2012.

[25] V. Ganesh, S. Sivanagaraju, and T. Ramana, "Feeder Reconfiguration for Loss Reduction in Unbalanced Distribution System Using Genetic Algorithm," International Journal of Electrical and Electronics Engineering, vol. 3, no. 12, pp. 754-762, 2009.

\section{BIOGRAPHIES OF AUTHORS}



Rudy Gianto (D) $\mathrm{Pl}$ SC $\mathrm{P}$ received $\mathrm{BE}, \mathrm{ME}$ and $\mathrm{PhD}$ degrees from Tanjungpura University in 1991, Bandung Institute of Technology in 1995, and The University of Western Australia in 2009 respectively. Currently, he is an Associate Professor at Tanjungpura University, Indonesia. His research interests include power system analysis, simulation of power system dynamics, and distributed generation. He has published many research papers in international journals and conferences. He can be contacted at email: rudy.gianto@ee.untan.ac.id.

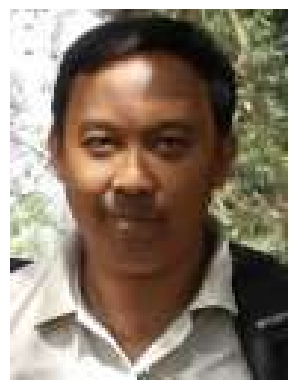

Purwoharjono (D) SC $\mathrm{P}$ received $\mathrm{BE}, \mathrm{ME}$ and Doctor degrees from Tanjungpura University in 1997, Institut Teknologi Sepuluh November in 2001, and 2014 respectively. Currently, he is an Associate Professor at Tanjungpura University, Indonesia. He has published several international journal and conference papers. His research interests include power flow analysis, and system optimizations. He can be contacted at email: purwoharjono@gmail.com. 